\title{
Systemic sarcoidosis induced by etanercept: first Brazilian case report ${ }^{*}$ \\ Sarcoidose sistêmica induzida por etanercepte: primeiro relato de caso brasileiro
}

\author{
Natasha Unterstell ${ }^{1}$ \\ Pérola Peres da Fonseca e Castro ${ }^{1}$
}

\author{
Aline Lopes Bressan ${ }^{2}$ \\ Alexandre Carlos Gripp ${ }^{3}$
}

Laura Araújo Serpa ${ }^{1}$

DOI: $h$ ttp://dx.doi.org/10.1590/abd1806-4841.20132588

\begin{abstract}
The antagonists of tumor necrosis factor alpha (TNF- $\alpha)$ are increasingly being used in the treatment of inflammatory and autoimmune diseases. Several adverse effects of these drugs have been reported, including the paradoxical development of sarcoidosis, especially with the use of etanercept. We present the first Brazilian case report of systemic sarcoidosis induced by etanercept and a literature review.

Keywords: Diagnosis; Granuloma; Sarcoidosis; Tumor necrosis factor-alpha

Resumo: Os medicamentos antagonistas do fator de necrose tumoral alfa (TNF- $\alpha$ ) estão sendo cada vez mais utilizados no tratamento de doenças inflamatórias e autoimunes. Efeitos adversos desses medicamentos vem sendo relatados, incluindo o desenvolvimento paradoxal de sarcoidose, principalmente com o uso do etanercepte. Apresentamos o primeiro relato de caso brasileiro de sarcoidose sistêmica induzida por etanercepte e uma revisão da literatura.

Palavras-chave: Diagnóstico; Fator de necrose tumoral alfa; Granuloma; Sarcoidose
\end{abstract}

\section{BACKGROUND}

Sarcoidosis is a multisystem disease of unknown etiology, characterized by the formation of noncaseating granulomas, especially in the lungs, lymphnodes, eyes and skin. ${ }^{1}$ Tumor necrosis factor antagonists (anti-TNF) may be used as treatment, however some cases of sarcoidosis secondary to these same drugs have been detected..$^{1-8}$ We report the case of a female patient, with rheumatoid arthritis presenting with systemic sarcoidosis after 6 months of treatment with etanercept.

\section{CASE REPORT}

A fifty year-old female patient, Caucasian, born in Rio de Janeiro, was diagnosed with rheumatoid arthritis 10 years ago. She started treatment with weekly etanercept $50 \mathrm{mg}$ subcutaneously over one year ago, due to a poor therapeutic response to methotrexate, sulphasalazine and corticoids. Prior to starting the immunobiologic therapy, the patient was screened with thoracic radiographies, PPD and HIV and hepatitis serologic tests, all with normal results.

After 6 months of treatment with etanercept, infiltrated erythematous lesions appeared surrounding a scar on the posterior region of the right thigh and right gluteal area, followed by the emergence of painful erythematous nodules on lower limbs and an increase of volume on the neck (Figures 1 and 2). Our patient denied fever, weight loss and dyspnea. At this point, thoracic and cervical computerized tomography scans were performed, showing pulmonary perihilar lymphadenomegaly and bilateral augmentation of parotids without lymphadenomegaly, respectively (Figure 3). Histopathological examination of the right thigh skin lesion demonstrated the presence of noncaseating granulomas formed by histiocytes and giant cells in the dermis and hypodermis (Figures 4 and 5).

Received on 05.03.2013.

Approved by the Advisory Board and accepted for publication on 02.04.2013.

* Work performed at Pedro Ernesto University Hospital- Rio de Janeiro State University (HUPE-UERJ) - Rio de Janeiro (RJ), Brazil

Conflict of interest: None

Financial Support: None

MD, resident on the Dermatology Program at Pedro Ernesto University Hospital- Rio de Janeiro State University (HUPE-UERJ) - Rio de Janeiro (RJ), Brazil.

MD, dermatologist - Attendant at the dermatology ward and the immunotherapy clinic at Pedro Ernesto University Hospital- Rio de Janeiro State University (HUPE-UERJ) - Rio de Janeiro (RJ), Brazil.

MD, MSc in dermatology - Chief of the dermatology ward and immunotherapy clinic at Pedro Ernesto University Hospital- Rio de Janeiro State University (HUPE-UERJ) - Rio de Janeiro (RJ), Brazil. 


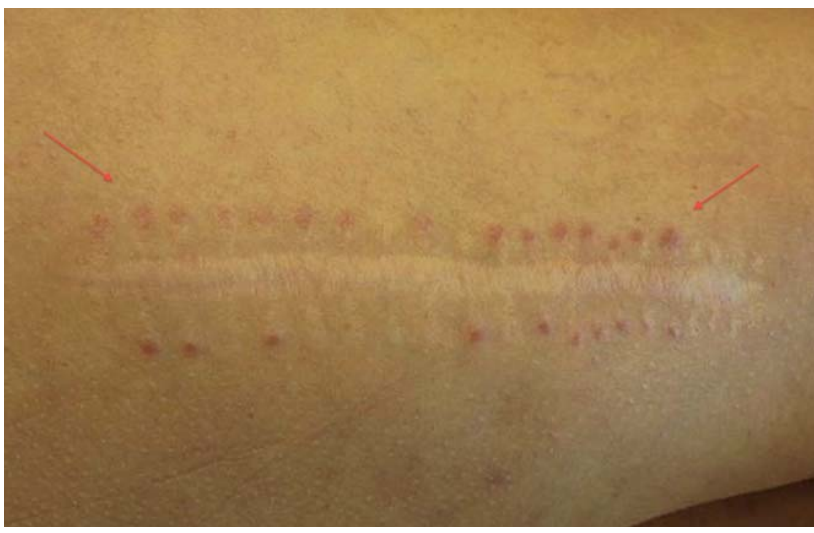

FIGURE 1: Erythematous, infiltrated lesions surrounding a cicatricial area on the posterior region of the right thigh
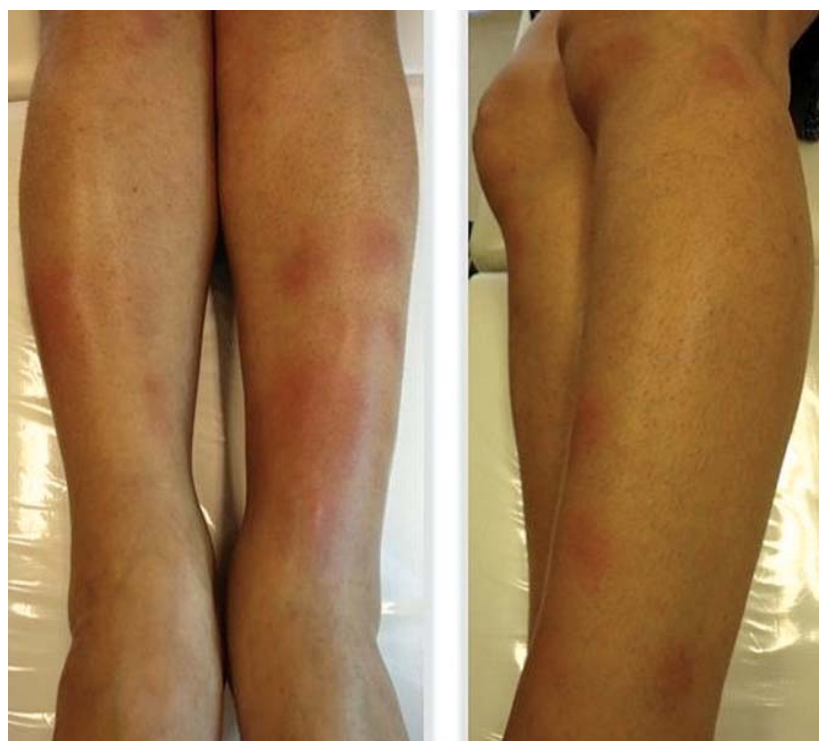

FIGURE 2: Erythema nodosum on lower limbs

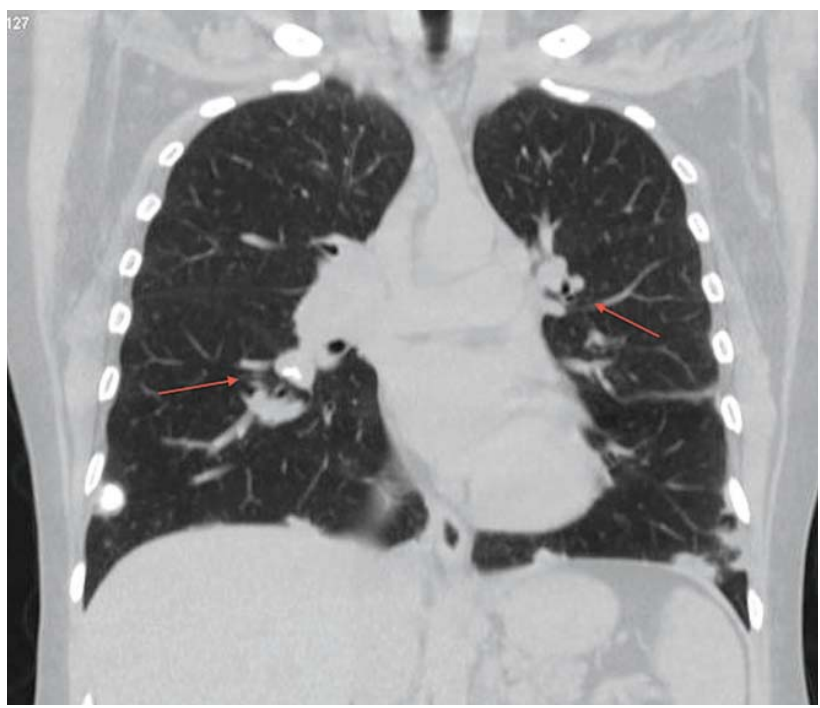

FIgURE 3: Thoracic CT scan showing perihilar pulmonary lymphadenomegaly

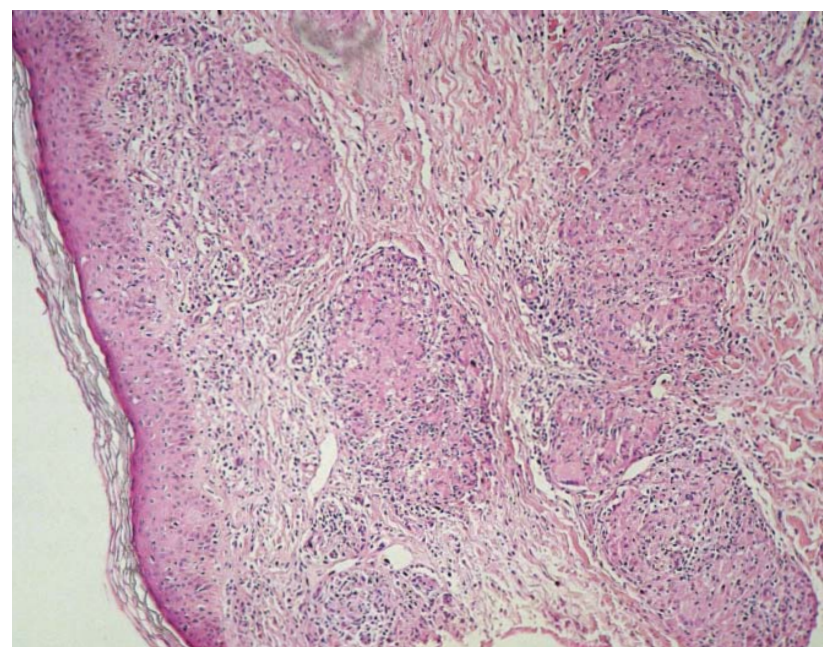

FIGURE 4: Histopathological exam (100x zoom) of the right thigh lesion showing well-delimitated, noncaseating granulomas in the dermis and hypodermis

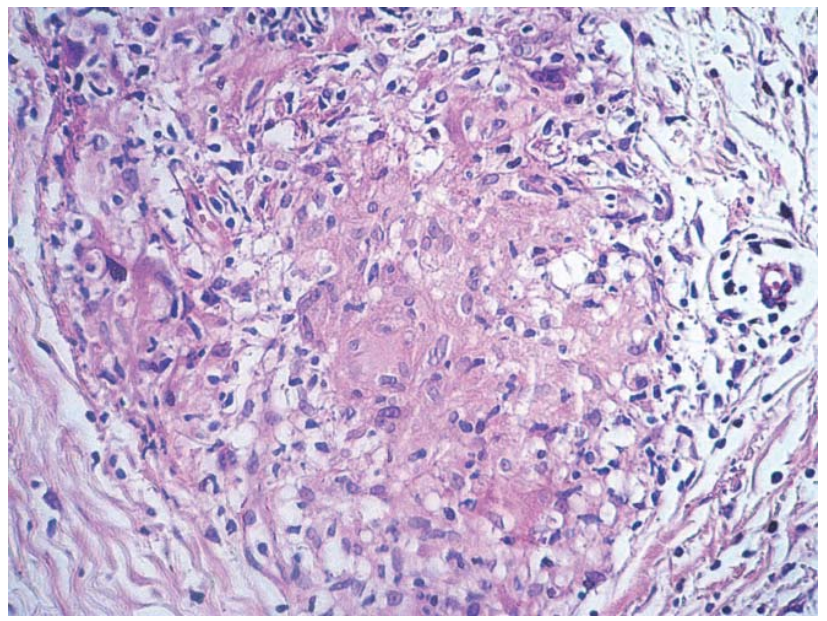

FIGURE 5: Histopathological exam (1000x zoom): noncaseating granuloma formed by histiocytes and giant cells

Skin cultures for mycobacteria and fungi were negative and angiotensin converting enzyme levels were $61 \mathrm{U} / \mathrm{L}$ (reference value: < $60 \mathrm{U} / \mathrm{L}$ ).

Etanercept was suspended after the diagnosis of sarcoidosis, and treatment with prednisone 30$\mathrm{mg} /$ day p.o. was initiated resulting in an improvement of skin, cervical and pulmonary lesions within approximately 30 days.

The dose of prednisone was gradually reduced after 3 months, and no relapse of symptoms was observed after 6 months of follow-up.

\section{DISCUSSION}

The exact etiology of sarcoidosis remains unknown. It is believed that an exacerbated immune response may occur due to antigenic stimuli such as infectious and environmental agents and also autoantigens. ${ }^{1}$ 
Recent studies demonstrated that TNF- $\alpha$ has a crucial role in forming the inflammatory granuloma, as well as in regulating adhesion molecules, recruiting cells and activating lymphocytes. ${ }^{9}$

The formation of the granuloma requires a cellular type (Th1) response pattern; involving macrophages and T CD4 activated lymphocytes. Interleukin- $1 \mathrm{~b}$ and gamma-interferon are important promoters during the initial phases of the granuloma development; TNF- $\alpha$ on the other hand, is critical during the latter phases of the granulomatous process. $^{10}$

Tumor necrosis factor antagonists (anti-TNF) are used to treat sarcoidosis since; in theory, they would block this cytokine's action. ${ }^{1,2,3}$ However, paradoxically, some cases of sarcoidosis induced by these same medications have been reported. ${ }^{8}$ This perplexing mechanism is not yet clear, but it is believed that these drugs do not inhibit all the signaling pathways of TNF- $\alpha$, thus ensuing some "escape" routes. ${ }^{2-8}$

In a review published on May 2012, (Cathcart, et $\left.a l^{6}\right), 34$ cases of sarcoidosis induced by TNF- $\alpha$ antagonists had already been described on the medical literature. Twenty-one of those $(61.7 \%)$ occurred after the use of etanercept, $9(26.4 \%)$ after infliximab and $4(11.7 \%)$ after adalimumab. In this study, the mean time for the appearance of granulomas was 22 months after the start of medications. ${ }^{6}$

After a literature review, we found 48 case reports of sarcoidosis induced by TNF- $\alpha$ antagonists. Thirty- one (64.58\%) followed etanercept, 9 (18.75\%)

\section{REFERENCES}

1. Daldon PEC; Arruda LHF. Noninfectious granulomas: sarcoidosis. An Bras Dermatol. 2007;82:559-71.

2. Aguiar M, Marçal N, Mendes AC, Bugalho de Almeida A. Infliximab for treating sarcoidosis patients, Portuguese experience. Rev Port Pneumol. 2011;17:85-93

3. Hostettler KE, Studler U, Tamm M, Brutsche MH. Long-term treatment with infliximab in patients with sarcoidosis. Respiration. 2012; 83:218-24.

4. Gifre L, Ruiz-Esquide V, Xaubet A, Gómez-Puerta JA, Hernández MV, Sanmartí R. Lung sarcoidosis induced by TNF antagonists in rheumatoid arthritis: a case presentation and a literature review. Arch Bronconeumol. 2011;47:208-12.

5. Fok KC, Ng WW, Henderson CJ, Connor SJ. Cutaneous sarcoidosis in a patient with ulcerative colitis on infliximab. J Crohns Colitis. 2012;6:708-12.

6. Cathcart S, Sami N, Elewski B. Sarcoidosis as an adverse effect of tumor necrosis factor inhibitors. J Drugs Dermatol. 2012;11:609-12.

7. Lamrock E, Brown P. Development of cutaneous sarcoidosis during treatment with tumor necrosis alpha factor antagonists. Australas J Dermatol. 2012;53:e87-90.

8. Massara A, Cavazzini L, La Corte R, Trotta F. Sarcoidosis appearing during anti-tumor necrosis factor alpha therapy: a new 'class effect' paradoxical phenomenon. Two case reports and literature review. Semin Arthritis Rheum. 2010;39:313-9.

9. Lukacs NW, Chensue SW, Strieter RM, Warmington K, Kunkel SL. Inflammatory granuloma formation is mediated by TNF-alpha-inducible intercellular adhesion molecule-1. J Immunol. 1994;152:5883-9.

10. Vigne C, Tebib JG, Pacheco Y, Coury F. Sarcoidosis: An underestimated and potentially severe side effect of anti-TNF-alpha therapy. Joint Bone Spine. 2013;80:104-7. occurred after infliximab and $8(16.66 \%)$ after adalimumab. Most patients had pulmonary and/or lymphnode involvement, with 8 cases of cutaneous manifestations, mainly of erythema nodosum. ${ }^{6,10}$

Despite all the anti-TNF drugs having the ability to block pro-inflammatory cytokine TNF- $\alpha$, they possess marked differences in their own structures, as well as their pharmacokinetics and pharmacodynamics' attributes, which explains, in part, the diversity that may be observed in clinical efficacy and adverse events, including the triggering of granulomatous lesions. $^{7}$

The inhibition of TNF- $\alpha$ by etanercept is not a complete one, since this drug connects only to the soluble TNF receptor and not to the transmembrane receptor, as occurs with infliximab and adalimumab. Partial neutralization of TNF- $\alpha$ by etanercept permits the redistribution of this cytokine in areas of lower concentration, such as the lungs. This may explain the stronger association of granulomatous reactions with the use of etanercept. ${ }^{8,10}$

The treatment of such cases has been the suspension of the anti-TNF agent and in some cases, as reported here, the introduction of corticoids. The mean time to recovery of symptoms after the interruption of the drug is 5.2 months. ${ }^{6}$

Considering that these drugs are increasingly used in dermatology, we must remain alert to the possibility of sarcoidosis, especially if respiratory symptoms, or erythema nodosum and/or granulomatous cutaneous eruptions arise. $\square$

How to cite this article: Unterstell N, Bressan AL, Serpa LA, Castro PPF, Gripp AC. Systemic sarcoidosis induced by etanercept: first Brazilian case report. An Bras Dermatol. 2013;88(6 Suppl 1):S197-9. 